\title{
ESTUDIOS
}

\section{Bernal Díaz del Castillo, o de la Verdad en la Historia}

La Historia verdadera de la conquista de Nueva España ha conocido extrañas vicisitudes de fortuna en los tres siglos que han transcurrido desde su publicación. A nadie puede sorprender el hecho de que, al principio, el relato del soldado cronista quedara relegado y oscurecido, y que durante los siglos xvir y xvir se prefirieran la Conquista de México de Francisco López de Gómara, o la Historia de la conquista de México de Antonio de Solís, dechados de agudeza incisiva y de elegancia retórica, respectivamente.

Casi total fue el eclipse de la Historia verdadera de la conquista de Nueva España en el siglo xviI. En la crítica española, salvo la opinión solitaria de Andrés González de Barcia, ${ }^{1}$ lo único 'que por entonces preocupaba era averiguar el valor de la obra como testimonio histórico. Después se despertaría el gusto por esa narración tosca, ingenua y verídica, cuando se marchitaran el ornato de las crónicas cultas, y sobre todo, en la segunda mitad del siglo xviIr, cuando se abrieran paso las ideas estéticas que exaltaban lo natural, primitivo y espontáneo como un nuevo linaje de belleza, antes desconocido.

Significativo es que fuera un historiador extranjero, William Robertson, quien declarara resueltamente que la Historia verdadera le pare-

1 En el Epitome de la Bibliotbeca oriental y occidental, náutica y geográfica de Antonio de León Pinelo, que añadió y enmendó Andrés González de Barcia, Madrid, $1737-1738$, t. II, col. 604 . 
cia "one of the most singular [books] that is be found in any language."'2 Porque en el extranjero, donde el libro circulaba en el siglo XIx en cuatro lenguas - con varias traducciones en algunas de ellas ${ }^{3}$ - creció la marea admirativa que impuso el nombre de Bernal Díaz como caso excepcional en la literatura española. En nuestros días, la Historia verdadera se reim. prime sin cesar en España y América, y siguen apareciendo traducciones enteras, o abreviadas y modernizadas. Así como alguna carta de Colón se versificó en octavas italianas, se ha compuesto modernamente en lengua inglesa una versión poética que combina los relatos de Bernal Díaz y de Prescott, 4 y en la legión de devotos de nuestro cronista se cuentan poetas distinguidos como Archibald MacLeish, cuyo poema Conquistador se inspiró en su lectura, y Saint John Perse. 5

El soldado de Cortés ha triunfado, pues, sobre los que en vida se atrevieron a disputarle la prioridad en el relato de las hazañas de su jefe y de sus compañeros, y tan completa ha sido su victoria, que sus resultados han llegado a alarmar a algunos de sus antiguos entusiastas. ${ }^{6}$ La crítica bernaldista no ha dejado, en más de un siglo de estudios, saldo demasiado fecundo; quien se proponga alinear algunas observaciones seguras y exactas sobre la Historia vardadera comprobará que aún dilatan el camino de su investigación graves interrogantes.

No se ha fijado aún el texto indudable; el libro surge de modo mis-

2 William Robertson, History of America, 1774, lib. V, n. IXIX.

3 Además de seis ediciones en español (tres en la capital de México, 1854, 1870, y 1891-92; dos en España, Madrid, 1852-53, y 1862-63; y una en Francia, París, 1837) se tradujo la Historia verdadera dos veces al inglés (M. Keatinge, 1800 , y John Ingram Lockhart, 1844) e igual número de veces al francés (D. Jourdanet, 1876, y José María de Heredia, 1877-1887), al alemán (P. I. Rehfues, 1843-44; y Karl Ritter, 1849), y al húngaro (Karoly Brozik, 1878, y Mozes Gaal, 1899). Y debe advertirse que algunas de esas traducciones se han reimprimido y abreviado. La lista proviene de la introducción de Joaquín Ramírez Cabañas a la Historia verdadera de la conquista de Nueva España, México, 1955, $4^{n}$ ed., p. 31-36.

- En la introducción de Albert Idell (New York, 1957) se refiere a la versión poética de Kinaham Cornwallis, The Conquest of Mexico and Peru.

5 Saint John Perse confesaba al llegar a los Estados Unidos que, al salir de Francia, había elegido la Historia verdadera como libro del que no podía desprenderse.

6 Ranón Iglesia, que había manifestado su entusiasmo por Bernal Díaz en su estudio Bernal Díaz y el popularismo en la bistoriografía española, en la revista Tierra Firme, Madrid, 1935, núm. 4, consideró luego excesivos algunos juicios suyos y los corrigió en Las criticas de Bernal Díaz del Castillo a la Historia de la conquista de México de López de Gómara: ambos estudios incluidos en su libro El bombre Colón y otros ensayos, México, 1944. Antes, en Cronistas e bistoriadores de la conquista de México, México, 1942, págs. $97-215$ había apreciado con simpatía la labor histórica del capellán de Cortés, iluminando rasgos valiosos de su fisonomía compleja de escritor. 
terioso, sesenta años después de muerto el autor, y envuelto en enigmas bibliográficos que no han podido explicarse. ${ }^{7}$ Sólo contamos con un diagnóstico aproximado de los manuscritos, en cuanto a su fecha y autenticidad, porque está aún inédita una copia descubierta hace un cuarto de siglo, que impide llegar a conclusiones definitivas sobre el problema fundamental de composición de la obra.

No es más fácil el análisis desde otro punto de vista. La Historia verdadera es, además de documento histórico, testimonio valioso para el estudio del español de la primera mitad del siglo xvi; y especialmente interesante, porque puede iluminar los primeros pasos en la evolución de la lengua en América.

Los textos de la Historia verdadera

El problema de los textos de la Historia verdadera y el de la tradición de los manuscritos merece considerarse aunque no pueda resolverse con los datos actuales, porque puede of recernos alguna luz para reconstruir el proceso de composición de la obra.

I. Desde el siglo Xvir, la crítica ha considerado poco fidedigno el texto de las dos primeras ediciones ( I $_{32}$ ) que el cronista de la Orden de la Merced fray Alonso Remón preparó antes de morir. Algunas copias de venerable apariencia ofrecían diferentes lecturas que se declararon inmediatamente preferibles. En cuanto se comprobó que el editor había introducido retoques en los originales, sobre todo interpolaciones destinadas a subrayar la participación de su hermano de orden fray Bartolomé de Olmedo en los sucesos de la Conquista, los impresos se descartaron por sospechosos ante los manuscritos intachables. 8 Desgraciadamente, la

7 El primero, que sólo puede enunciarse por ahora, es el de las dos ediciones de la Historia verdadera, las dos, obra de fray Alonso Remón - que acababa de faIlecer-salidas de la Imprenta del Reino y dedicadas a Felipe IV; una sin fecha, con 212 capítulos y con la portada grabada por Juan de Courbes, y otta de 1632, con el mismo texto y además otro capítulo añadido - se tiene por apócrifo-y con diferente portada. No se sabe cómo explicar estas singularidades. Véase Historia verdadera, México, 1904, Noticias bibliográticas, I, págs. LXIX-LXXIX, y José Toribio Medina, Biblioteca bispano-americana, I, 340, y 340-351.

8 Impugnaron la edición príncipe el cronista guatemalteco Francisco Antonio de Fuentes y Guzmán (1643-¿1700?), tataranieto de Bernal Díaz, el fraile dominico 
cuestión es mucho más compleja. Porque hay otras divergencias -además de las señaladas - en las que el texto de las copias aparece en el impreso ampliado, reducido, mejorado, empeorado o distinto, y frente a ellas hay que admitir simplemente - sin perjuicio de las enmiendas interesadasque el manuscrito que fray Alonso Remón usaba difería de los que han surgido después.

En primer lugar, en la versión del cronista mercedario, la Historia aparece dividida en 2 I 2 capítulos, con un prólogo fechado el 26 de febrero de ${ }_{5} 68$ en el que el autor declara: ". . se acabó de sacar en limpio de mi memoria y borradores..."; y advierte además: ". . tengo que acabar ciertas cosas que faltan, que aún no se han acabado, va en muchas partes testado, lo cual no se ha de leer", rasgos fundamentales que permite clasificar los manuscritos. No es del todo seguro que esa copia sea la misma que el autor hizo para la Audiencia de Guatemala, y se envió al Consejo de Indias en $1579 ;^{\circ}$ pero no puede ser sino la que fray Alonso Remón dijo haber obtenido del Consejero de Indias Lorenzo Ramírez de Prado, en poder de quien estaba todavía en 1629 , ya "corregida", según Antonio de León Pinelo. ${ }^{10}$

Sobre la edición de ese manuscrito se han basado todas las reimpresiones españolas e hispanoamericanas, y las traducciones en otras lenguas de los siglos XVII y XIX, y entre ellas, la de la Bibliotieca de autores españoles, que popularizó el texto de Fray Alonso Remón y que usaremos principalmente en adelante, en defecto de la edición príncipe, que también hemos consultado. ${ }^{11}$

autor del Isagoge bistórico apologético (¿1700-1711?) y el cronista franciscano fray Francisco Vázquez; los tres notan diferencias con los manuscritos: Fuentes y Guzmán y Vázquez señalan contradicciones entre los caps. 164 y 171 del impreso, que no se observan en las copias, además de otras diferencias, respecto a la participación de fray Bartolomé de Olmedo en la conquista de Guatemala. Fuentes y Guzmán usa un "borrador original" y otra copia en poder de la familia (véase infra, nota 14); fray Francisco Vázquez parece no conocer el "borrador", porque dice que el original tenía 211 capítulos (Crónica de la Provincia del Santísimo Nombre de Jesüs (1714-1716), ed. Biblioteca Goatbemala, I, pág. 23.) Alegó estos testimonios y añadió otros para probar las interpolaciones maliciosas de fray Alonso Remón, el historiador mexicano Genaro García, en las Noticias biobibliográficas de su edición de.la Historict verdadera. México, 1904, XII-XIV, LXIXLXXVII, y apéndice núm. 2, XC-CXVI.

9 Salvo que se copiara antes de 1568, fecha en que se añadieron los caps. 213 y 214 , pero no se enviará a España hasta 1579.

10 Antonio de León Pinelo, Epitome de la bibliotbeca oriental y occidental, Madrid, 1629, pág. 75, cit. por Genaro García, loc. cit.

11. Véase la lista de las ediciones, en Ramírez Cabañas, introducción a su ed. de la Historia verdadera, loc. cit. 
2. Los manuscritos que atestiguaban fehacientemente la adulteración de los impresos tenían, sin duda, títulos innegables de autenticidad. El llamado "borrador", que se conserva en Guatemala, está autorizado con la firma del autor, se considera autógrafo, y se transmitió durante el siglo Xvil como reliquia familiar entre los descendientes de Bernal Díaz, cua. lidades que contrastan con la historia incierta del primer impreso. La redacción del "borrador" comprende dos capítulos finales añadidos a los doscientos doce de la edición de Remón, y un prólogo distinto del que lleva el impreso: los dos capítulos se agregaron después de 1568; el prólogo, donde el autor dice que tiene ochenta y cuatro años y que ha perdido la vista y el oído, debe haberse compuesto hacia 1580 . Puede no haber sido el original, pero se convirtió en borrador, a juzgar por las numerosas enmiendas; $y$ fue la matriz de varias copias. ${ }^{1.2}$ Hay varias descripciones, no muy completas, del "borrador", desde la que le proproporcionaron al poeta cubano francés José María Heredia; ${ }^{13}$ y, a partir de la edición excelente de Genaro García, ${ }^{1 / 4}$ sustituyó como único texto auténtico al de la edición príncipe, y lo han reproducido todas las ediciones del siglo $\mathrm{xx} .^{15}$

En el manuscrito de Guatemala se reflejan varios períodos de composición de la obra, anteriores y posteriores a la versión independiente que serviría para el puimer impreso. Bernal Díaz pasó largo tiempo sobre su Historia - unos treinta años; y después de haberse desprendido de la copia que fue a España, siguió revisando el texto, añadiendo o quitando párrafos, alterando, y a menudo incurriendo en repeticiones o perjudicando gravemente el sentido original. ${ }^{16}$

12 En el "bortador", a continuación de la firma del autor hay una nota de letra distinta que dice: "Acabóse de sacar esta Historia en Guatemala a 14 de noviembre de 1605." Siguiendo la costumbre de anotar al margen de la escritura original los testimonios que se sacan de ella, el copista o el poseedor del manuscrito deịaron constancia de que hubo una copia de esa fecha. Véase además, la nota 18.

13 La primera descripción del manuscrito de Guatemala, en los preliminares de la traducción francesa de José María de Heredia (Véridique bistoire de la conquête de la Nouvelle Espagne, París, 1877-87, 4 vs.).

14 Bernal Díaz del Castillo, Historia verdadera de la conquista de la Nueva España por... uno de sus conquistadores, única edición hecha según el códice autógrafo, México, 1904, 2 vs.

115 Por ejemplo, la modernizada de la "Biblioteca Goathemala", IX, X y XI, con prólogo de Eduardo Mayora, Guatemala, 1933-34, y la traducción de A. P. Maudsley (Londres, 1908, Hakluyt Society). De las restantes, son las mejores, las de Joaquín Ramírez Cabañas: utilizo la de México, 1955 y conozco dos anteriores de 1944 y 1950.

16 En general, el texto de Guatemala amplifica el de la edición príncipe, pero en algunos lugares ocurre lo contrario. Las más largas refundiciones ampliatorias se encuentran en los caps. I, VIII, y CXLII; se ven claras las dos redacciones inde- 
3. Casi treinta años transcurrieron después de la aparición del manuscrito de Guatemala en la edición de Genaro García, cuando se descubrió en Murcia el manuscrito, hasta entonces desconocido, de José Alegría, aún inédito. ${ }^{17}$ Por lo que parece de las descripciones muy incompletas que se han publicado, esa nueva copia no modificaria fundamentalmente el estado actual del problema, aunque será preciosa para depurar el texto de la futura edición crítica, puesto que sería el "traslado en limpio" que Francisco Antonio de Fuentes y Guzmán conoció en poder de la familia de Bernal Díaz, ${ }^{18}$ desciende del "borrador" y completa su sentido: ${ }^{19}$

En resumen, conservamos a través de los manuscritos, rastros de dos etapas en el larguísimo proceso de composición de la Historia: a) la que reflejaría, aproximadamente, la edición príncipe, si pudiéramos depurarla de sus enmiendas interesadas: es la versión más antigua, con un texto más breve, que Bernal Díaz debió juzgar perdida en España; y b) la que el autor siguió corrigiendo casi treinta años, representada por el "borrador", corregido con el manuscrito de Alegría, y cotejado con el impreso.

pendientes, en los caps. VIII y LXXXIII, y sobre todo, en el cap. CCIII donde, afortunadamente han quedado los dos textos: el que está tachado y se reproduce en nota, coincide con la edición príncipe, que en este caso ofrece una lección más clara y completa. Historia verdadera, ed. Garcia, II, 430-31.

17 En el Centro de Estudios Históricos de Madrid se preparaba por entonces una edición crítica de los textos de Guatemala y de la primera edición, y cuando estaba bastante avanzada la tarea, hubo que rehacerla, ante el hallazgo de la nueva copia de Alegría; desgraciadamente, el trabajo se interrumpió por el éxodo de los colaboradores en 1935, y no se ha completado hasta ahora. El único tomo de la edición crítica que ha aparecido, lo publicó el Consejo Superior de Investigaciones Científicas, Instituto Gonzalo Fernández de Oviedo: Historia verdadera de la conquista de la Nueva España, Madrid, MCMXL.

18 Francisco Antonio de Fuentes y Guzmán, loc. cit., habla de un "traslado en limpio que se sacó por el que se envió a España para Ia primera impresión, para remitir duplicado, que, no habiendo ido, conservan los hijos de doña María del Castillo, los deudos, autorizado por la firma del Sr. don Ambrosio Díaz del Casti. llo... Deán que fue de esta Santa Iglesia Catedral primitiva de Goathemala".

19 Según Carmelo Sáenz de Santa María, esa copia es la que se envió a España a ruego de Juan Bautista Muñoz hacia 1797: la considera "hecha a la vista del autor y conforme con sus últimas opiniones, o una copia hecha a comienzos del siglo siguiente (la de 1605) veinte años después de la muerte de Bernal Díaz..."; y "representa ... la redacción definitiva del códice de Guatemala, después de cumplidas escrupulosamente las indicaciones (correcciones, tachaduras, marginales) en que es tan prolijo el autógrafo," Misceláned americanista, Instituto Gonzalo Fernán. dez de Oviedo, Madrid, 1951, págs. 363-381. Según Ramírez Cabañas (ed. cit.), sin embargo, el manuscrito Alegría concluye con el cap. 212, lo que obliga a pensar que se desprendió del borrador de Guatemala al mismo tiempo que la copia de fray Alonso Remón, y sin duda hacia 1568. 
Bernal Díaz, veinte años después de la conquista de México

Hacia mediados del siglo xvr, Bernal Díaz del Castillo sobrevivía como testigo excepcional de los sucesos de la conquista de Nueva España. En esa nobleza de Indias, que graduaba sus títulos según la antigüedad de su llegada a la tierra, y de acuerdo con las batallas libradas, Bernal Díaz llegó a sobrepasar a todos los que quedaban: era el más "antiguo", y además, podía certificar su asistencia a ciento diez y nueve combates, que contaba y recontaba sin cesar, con diferentes resultados, en cuanto los enumeraba; sólo en cincuenta y tres se había hallado Julio César, a juzgar por los Comentarios afirmaba orgullosamente. ${ }^{20}$

Aunque admitiera que él había sido originariamente uno de los soldados oscuros y pobres - no tenía encomiendas en Cuba, ni era de los "principales" - en la vejez se consideraba ennoblecido con sus méritos más que suficientes, porque finalmente, como nos dice previniendo reparos: “. . éramos todos los más, hijosdalgos, aunque algunos no pueden ser de tan claros linajes; porque vista cosa es que en este mundo no nasçen todos los hombres yguales, ansí en generosidad como en virtudes." 21

Como a ningún otro entre los vivos, le había correspondido casualmente intervenir en las dos primeras - y poco provechosas - armadas de exploración (de Francisco Hernández de Córdoba, 1517; y de Juan de Grijalva, I5I8); había estado también en el tercer viaje, en el decisivo e inolvidable de Hernán Cortés, y no había faltado a las peripecias más importantes (ninguna como los noventa y tres días de asedio a la gran ciudad de Tenochtitlán); y todavía, sin mencionar algunas expediciones intermedias, había interrumpido su retiro para culminar sus trabajos marchando con Hernán Cortés a la desastrosa expedición a las Higueras (I524-I526).

Podía, pues, decir una y otra vez, golpeándose el pecho:

Digo que ningún soldado pasó a esta Nueva España tres veces arreo, una

20 En la edición de Remón decía "Por manera que a la cuenta que en esta relación hallarán, me he hallado en ciento diez y nueve batallas y reencuentros de guerra, y no es mucho que me alabe de ello, pues es la pura verdad" ... (B.A.E., XXVI, 317): en la redacción del ms. de Guatemala, en ese capítulo, totalmente refundido, ese párrafo final desapareció, sustituido por otra enumeración de batallas, que duplica y se añade a la anterior (ed. Genaro García, II, 501-507).

21. Historia verdadera, ed. García, II, cap. CCVII, 473. 
tras otra como yo; por manera que soy el más antiguo descubridor y conquistador que hay en Nueva España, puesto que muchos soldados pasaron dos veces a descubrir, la una con Juan de Grijalva, ya por mi memorado, y la otra con el valeroso Hetnán Cortés, mas no todas tres veces arteo, porque si vino al principio con Francisco Hernández de Córdoba no vino la segunda con Grijalva ni la tercera con el esforzado Cortés. ${ }^{22}$

Y podía también añadir:

...entre los fuertes conquistadores mis compañeros, puesto que [aunque] los huvo muy esforçados, a mí me tenían en la cuenta dellos, y el más anti. guo de todos; y digo otra vez que yo, yo, y yo-dígolo tantas veces-que yo soy el más antiguo y lo he servido como muy buen soldado a Su Ma. jestad.23

¿Cuántos quedaban, de tantos compañeros suyos, soldados o capita. nes esforzados, famosos o anónimos?:

... de quinientos cincuenta soldados que pasamos con Cortés de la isla de Cuba no somos vivos hasta este año 1568 que estoy trasladando mi relación sino cinco, que todos los demás murieron en las guerras ya por mi dichas, en poder de indios, y fueron sacrificados a los ídolos y los demás murieron de sus muertes...; y los sepulcros... digo que son los vientres de los indios que los comieron las piernas e muslos, e brazos, y molledos, y pies y manos, y lo demás fueron sepultacios.

De los mil trescientos que pasaron con Pánfilo de Narváez -sin contar marineros- quedaron diez u once; de los de Garay - unos mil doscientos- los más habían muerto sacrificados por los indios en Pánuco; y de los quince que llegaron con Lucas Vázquez de Ayllón no sabía que ninguno viviera. Son palabras del autor, en diálogo con la Fama, a quien irónicamente presenta en una alegoría, deseosa de conocer los palacios, blasones y sepulcros de los conquistadores de México. ${ }^{24}$

... Y hágoos saber, excelente Fama - añade-que de todos los que he recontado ahora somos vivos de los de Cortés cinco, y estamos viejos y dolientes de enfermedades, y, lo peor de todo, muy pobres y cargados de hijos e hijas para casar, y nietos con poca renta y así pasamos nuestras vidas con trabajos y miserias...25

22 Párrafo añadido al cap. I: no aparece en la versión de Remón, y sí en la de Guatemala (B.A.E., XXVI, 1 y ed. García, I, 6-7).

23 Historia verdadera, ed. García, II, CCX, pág. 484

24 Historia verdadera, ed. García, II, CCX, pág. 485.

25 Op. cit., cap. CCX, pág. 486. 
Ése era el alarde de los restantes hacia mediados de siglo, y Bernal Díaz creía de su deber asumir la voz de esa muchedumbre de sombras de mártires oscuros, que era capaz de evocar uno por uno, con sus figuras, sus apodos y sus cualidades características. ${ }^{26}$

No le habian faltado decepciones, luego de ganada la ciudad de México. Bien recompensado, al principio, por Cortés y por Gonzalo de Sandoval, los dos jefes a quienes más quería, ${ }^{27}$ con fructíferos pueblos de indios, se los quitaron bruscamente, y obtuvo otros menos valiosos en compensación, después de largas reclamaciones, ${ }^{28}$ pero siguió insistiendo en ello por muchos años, y consiguió mejoras sucesivas, aunque sus quejas puedan hacernos creer lo contrario. Además, desde 1535 su matrimonio con Teresa Becerra, hija de uno de los encomenderos ricos de Guate. mala, debe haber contribuido a darle cierta holgura.

Es significativo, por ejemplo, que a partir de cierta fecha no aspirara sino a cargos honoríficos; en 1542 pretendía el nombramiento de "criado de Su Majestad", y en I $55^{8}$ y en I 567 usaba ese título; fue regidor del cabildo en la Villa del Espíritu Santo, en Tabasco, hasta su primer viaje a España (I540), y volvieron a elegirlo a su regreso en la ciudad de Santiago de Guatemala, donde fue vecino los restantes años de su vida, hasta I584; era, además, "fiel ejecutor" de la Audiencia (1558); pidió el cargo en perpetuidad, y lo logtó.

Además de los métitos que alegaba, no le faltaron valedores en México - Cortés, el primer Virrey; el presidente de la Segunda Audiencia, Se: bastián Ramírez de Fuenleal-; y los tuvo también en la Corte. A menudo se enredaba en pleitos con las autoridades locales y elevaba sus reclama-

26 Historia verdadera, cap. $\mathrm{CCV}$, ed. García, "De los valerosos capitanes y fuertes y esforzados soldados que pasamos desde la isla de Cuba con el venturoso y animoso Don Hernán Cortés, que después de ganado México fue Marqués del Valle y turo otros dictados", y cap. CCVI, "De las estaturas y proporciones que tuvieron ciertos capitanes y fuertes soldados y de qué edades serían cuando venimos a conquistar la Nueva España", págs. 445-472.

27 Hernán Cortés le dio en encomienda el pueblo de Tlalpa en Tabasco (1522) y después recibió el de Cbamula, en Chiapas, y dos estancias (1523), que le quitaron Baltasar de Osorio y Diego de Mazariegos para agregarlos a las nuevas gober. naciones de Tabasco y Chiapas respectivamente (1527).

28 Recibió en cambio Gualpitán y Micapa en Cachula, y Popoloapán en Cintla, del tesorero Alonso de Estrada (1529). En 1540 marchó a la Corte con probanzas de servicio y cartas - una de Cortés, y otra del Virrey-y obtuvo reales cédulas de recomendación. En 1550 tenía encomiendas en Zacatepeque, Juanagazapa, y Misten, sin contar las que su mujer Teresa Becerra, hija de uno de los más ricos conquistadores de Guatemala, había heredado de su padre. Véase Historia verdadera, ed. México, 1955. Introducción Ramírez Cabañas, I, 12, y apéndice II. 
ciones a España, donde también tenía amigos influyentes: era deudo suyo el licenciado Gutiérrez Velázquez, del Consejo de Indias, y tenía vieja amistad desde los años de Cuba con el P. Las Casas, con quien sostenía correspondencia. ${ }^{29}$

En 1559, varios testigos de la información de su hijo Francisco Díaz del Castillo describen su casa como la de un encomendero tico, y uno de ellos dice que por entonces Francisco "padece necesidades hasta que suceda por muerte al dicho su padre en la encomienda de los indios". 30 En consecuencia, hay que conceder muy relativo valor a las repetidas quejas de Bernal Díaz, atribuyéndolas a su índole descontentadiza, que así como le provocaba conflictos con sus vecinos, también debía deformarle apasionadamente su visión de los hechos en que había participado.

Era un soldado que conservaba celosamente intactos los resabios adquiridos en la milicia, y que probablemente cultivara esos rasgos de su fisonomía, como los más notables entre los suyos, puesto que se relacionaban con los más honrosos años de su vida.

Son muy conocidos los trazos caricaturescos de la imagen del soldado en la comedia y la novela picaresca española en los siglos Xvi y xvII: algunos reconocemos en la de Bernal Díaz. Por ejemplo, dice:

... quedé tan acostumbrado a andar armado y dormir de la manera que he dicho, que después de conquistada la Nueva España tenía por costumbre de me acostar vestido y sin cama, e que dormía mejor que en colchones. E agora, cuando voy a los pueblos de mi encomienda no llevo cama, e si algu. na vez la llevo no es por mi voluntad sino por algunos caballeros que se hallan presentes, porque no vean que por falta de cama la dejo de llevar, mas en verdad que me echo vestido en ella; y otta cosa digo, que no puedo dormir sino un rato por la noche, que me tenga de levantar a ver el cielo y estrellas e me he de pasear un rato al sereno, y esto sin poner en la cabeza cosa ninguna de boñete ni paño, y gtacias a Dios, no me hace mal por la costumbre que tenía. ${ }^{31}$

Le había tocado ser testigo y actor en una de las más estupendas hazañas que el hombre haya cumplido; había ayudado a alcanzar enormes

29 Historia verdadera, ed. Ramírez Cabañas, docs. cit. en apéndice, II, págs. 433-477.

30 Ya reaccionaron contra la leyenda de la pobreza de Bernal Díaz, Ramírez Cabañas, introducción a su ed. de México, 1955, págs. 11-13, y Ramón Iglesia, Introducción al estudio de Bernal Diaz del Castillo y de su Verdadera bistoria, en El bombre Colón y otros ensayos, págs. 109-111.

31. Historia verdadera, ed. García, I, pág. 353. 
riquezas, ${ }^{32}$ que pocos habían gozado y a los más se les habían escurrido de entre las manos al punto de reunirlas. Con la carga de ese recuerdo, no podía fácilmente acomodarse a una existencia comunal, de holgada medianía, sin bruscas transiciones ni sobresaltos. Hay que imaginarlo en esos años, tan poco avenido con la tranquilidad monótona de Guatemala, como podría estarlo un veterano de la guardia de Napoleón, retirado a una granja de provincia en tiempo de Luis Felipe.

Tendía a exagerar las molestias de su condición actual, y se lamentaba de ello, como todos los sobrevivientes de la conquista, los ricos y los pobres. ${ }^{33}$

En una carta a fray Bartolomé de las Casas se presentaba "viejo, y muy cargado de hijos e de nietos, e de mujer moza, e muy alcanzado [apremiado de dinero] por tener probe tasación [en los tributos que le correspondían por los indios]... 34 $\mathrm{Y}$ en su Historia:

... diré con tristeza de mi corazón, porque me veo pobte y muy viejo y una hija para casar: y los hijos varones grandes y con barbas, y otros por criar, y no puedo ir a Castilla ante Su Majestad para representarle cosa cumplida a su real servicio y también porque me hagan mercedes, pues se me deben bien debidas... $3 \mathbf{3 5}$

Bernal Díaz del Castillo tenía cincuenta y cuatro años cuando volvió de su segundo viaje a España en I550, después de asistir a la Junta de Valladolid, como el "conquistador más antiguo de la Nueva España"; la opinión del soldado de Cortés había alternado allí con las de personas

32 "... después que el rey Salomón fabricó y mandó hacer el sacro templo de Jerusalem con el oro y plata que le trajeron de las islas Tarsis, Ofir y Saba no se ha oído en ninguna escritura antigua que más oro y plata y riquezas hayan ido cotidianamente a Castilla que destas tietras..." Historia verdadera, CCX, pág. 484.

33 Como ejemplo, véase la relación quejumbrosa que todos los conquistadores - con indios o sin ellos- hicieron al Virrey Antonio de Mendoza ante la perspectiva de un nuevo reparto, y que transcribe Francisco A. de Icaza, Diccionario biográfico de conquistadores y pobladores de Nueva España, Madrid, 1923, 2v.

34 Historia verdadera, ed. México, 1955, II, pág. 453.

35 Historia verdadera, ed. García, II, cap. CCX, pág. 484.

36 Joaquín Pardo fue el primero en advertir que estaba equivocada la fecha de 1542 que desde Genaro García en adelante se aceptaba para el nacimiento de Bernal Díaz, y propuso la de 1496, apoyándose en probanzas inéditas en el Archivo Colonial de Guatemala, Historia verdadera, ed. México, 1955, II, pág. 477. Ramón Iglesia (op. cit., 102) considera que debe ser 1495 ó 1496, teniendo en cuenta que en la información de Leonor de Alvarado (4/VI/1563) dice tener 67 años. Adviértase, además, que en carta al Rey $(29 / 1 / 67)$ confiesa tener 72 años, lo que no daría 1495. 
tan graves como fray Bartolomé de las Casas y su compañero de cruzada fray Rodrigo de Ladrada; Vasco de Quiroga, obispo de Michoacán; el licenciado Pedro de la Gasca; fray Tomás de San Martín, obispo de Charcas; y los miembros del Consejo de Indias.

A su vuelta, en Guatemala, se puso a la tarea de poner por escrito sus recuerdos, si no había comenzado antes esa tarea; en todo caso, la continuó con mayor seguridad en sí mismo.

Alonso de Zorita, oidor en la Audiencia de los Confines entre 1553 y 1557 , dice en su Historia de la Nueva España:

Bernal Díaz del Castillo, vecino de Guatemala, donde tiene buen repartimiento ... me dijo... que escribía la historia de aquella tierta, y me mos tró parte de lo que tenía escrito; no sé si lo acabó, ni si ha salido a luz.\$77

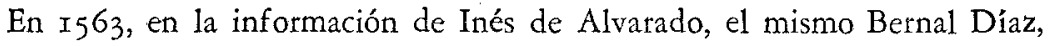
"vecino y regidor de Guatemala" se remite para justificar sus dichos sobre la guerra de Tlaxcala a "un memorial de guerras", que tiene escrito.38

Ya sabemos que, a juzgar por los capítulos finales y el prólogo de la edición príncipe, la primera redacción de la obra estaba concluida en 1568, y que siguió enmendando y corrigiendo sus manuscritos por muchos años; en I579 ó I 580 antepuso a su historia un breve prólogo ("porque soy viejo de más de ochenta y cuatro años y he perdido la vista y el oir") ${ }^{39}$ con lo que, como vemos, la Historia se nos presenta siempre en proceso de refundición por casi treinta años.

Casi al mismo tiempo, Juan Rodríguez Cabrillo de Medrano, testigo en la información de Bartolomé Becerra (I579), para manifestar su conocimiento de las campañas de Bernal Díaz, se apoya en "una crónica que el dicho... ha escrito y compuesto de la conquista de toda la Nueva España, que se envió a Su Majestad el rey don Felipe nuestro señor, la cual este testigo ha visto y leido." "'A0 Cuando murió, en I584, después de haber añadido dos capítulos, uno sobre los esclavos en Nueva España, y otro de reseña de los gobernadores de México, no había concluido su propósito de redactar otro sobre las autoridades eclesiásticas.

37 Cit. R. Iglesia, El bombre Colón, pág. 105.

38 Probanza de Inés de Alvarado, Historica verdadera, México, 1955, II, págs. 433-36.

39 Historia verdadera, ed. Genaro García, t. I. pág. 3.

40 Historia verdadera, México, 1955, II, pág. 464. 
Escribía despaciosamente, volviendo sobre lo escrito, pidiendo informes a los conquistadores de México, y sin otro plan que el de los "memoriales" de soldados, limitados a la mera sucesión de los hechos y comentario de las relaciones epistolares.

Para él ése fue siempre un libro abierto, como que su materia era inagotable, y porque no pensaba ajustarse a ninguna estructura historiográfica que pudiera imponerle la tradición literaria. "Estos no son cuentós viejos ni de muchos años pasados [es decir, leyendas], de historias romanas, ni ficciones de poetas' 41 decía recapitulando y echando una mirada sobre sus apuntes. No admitía que fueran leyendals; pero tampoco, literatura, ni debía juzgarse por sus normas ni ajustarse a sus exigencias.

Como lo que escribía era un memorial de servicios, el relato tomaba naturalmente intención ejemplar, y continuamente dejaba ver el propósito de servir de alegato. Así por ejemplo, concluye la narración de la expedición de Hernández de Córdoba:

...y diré que todos los soldados que fuimos en aquel viaje gastamos la po breza de hacienda que teniamos, y heridos y empeñados volvimos a Cuba; y cada soldado se fue por su parte y el capitán luego murió; estuvimos mu chos días curando heridas, y por mi cuenta hallamos que murieron cincuenta $\mathrm{y}$ siete. $\mathrm{Y}$ esta ganancia trajimos de esta entrada y descubrimiento. ${ }^{42}$

Y también se convertía en frecuentemente desordenada enumeración, algo así como los alardes, en los que el capitán contaba a los hombres, los caballos, y las armas antes o después del combate (cap. XXVIII y XXIII).

Cuando comenzó su narración, lo hizo directamente, sin introito, contando los sucesos de su viaje a las Indias: "En el año I5I4 salí de Castilla en compañía del gobernador Pedro Arias de Avila...", para concluirla con la muerte de Cortés (cap. CCIV), nómina de conquistadores (cap. CCV y CCVI) y relación de las batallas a las que el autor había asistido (cap. CCXII). Así era la primera redacción, la que refleja la edición príncipe.

Cuando Bernal Díaz vuelve sobre sus borradores, después de $1_{5} 68$, ha crecido en importancia: no es ya solamente uno de los que él llama "conquistadores verdaderos" y "sobresalientes"; era "el más antiguo"

1 Historid verdaderd, cap. CCXII, pág. 317.

42 Historia verdadera, cap. I. 
en un grupo de cinco. Tenía una situación económica segura, había recibido distinciones, y pedía otras, para que en su persona se desagraviara a sus compañeros muertos sin recompensa. $Y$ como ya sabe que él sólo puede of recer un relato verídico-hermoso porque es verdaderoy se siente por encima de los cronistas rivales, ensaya un breve prólogo distinto del anterior, porque ahora la suya es una "crónica" y no ya un "memorial":

Notando he estado cómo los muy afamados coronistas antes que comiencen a escribir sus historias hacen primero su prólogo y preámbulo con razones y retórica muy subida para dar luz a sus razones, porque los cuidosos lectores que las leyeren tomen melodia y sabor de ellas; y yo como no soy latino. no me atrevo a hacer preámbulo ni prólogo de ello .. .43

Modificará también el comienzo original, para colocarse él en primer lugar, como actor y autor, con su patria y genealogia:

Bernal Díaz del Castillo, vecino y regidor de la muy leal ciudad de Santiago de Guatemala, uno de los primeros descubridores y conquistadores de la Nueva España y sus provincias, y Cabo de Honduras e Higueras, que en esta tierra así se nombra, natural de la muy noble $e$ insigne villa de Medina del Campo, hijo de Francisco Díaz del Castillo, regidor que fue de ella, que por otro nombre se llamaba el Galán, y de María Rejón, su legítima mujer, que hayan santa gloria...

En resumen, la Historia verdadera no es la obra indignada y rápida que un viejo conquistador escribe ex abrupto, confiado en su memoria felicísima, y que se lanza a escribir, sólo para desmentir los errores que ha encontrado en varios libros sobre la conquista, cuyos autores no han salido de Europa, y donde los hechos aparecen deformados: ha llegado a decirse que "la indignación le hizo autor".

Es un libro muchas veces releído y revisado, durante largos años, y se pensó inicialmente como una minuciosa relación de méritos y servicios. Cuando se planeó, el autor no había visto obras impresas sobre los sucesos que contaba; y tampoco creia necesitar auxilio alguno para recordar hechos que no hacía sino revivir, como si lo que estuviera pasando fuera nada más que el epílogo de esos años luminosos.

A sus contemporáneos, los vecinos de Guatemala, podía sorprender-

43 Historia verdadera, ed. García, I, 3.

44 Histaria verdadera, ed. Garcia, I, 4. 
les esa memoria especializada en recordar nombres y figuras - la del militar, como la del profesor-y a ellos se dirige para darle ejemplos ilustres de ese hábito contraído en la vida de soldado:

... decian las historias que dellos han escrito que Mitrídates, rey del Ponto, fue uno de los que conocían a sus ejércitos, y otro fue el Rey de los epirotas, y por otro nombre se decía Alejandro. También dicen que Aníbal, gran capitán de Cartago, conocía a todos sus soldados, y en nuestros tiempos, el esforzado y gran capitán Gonzalo Hernández de Córdoba conocía a todos los más soldados que traía en sus capitanías; y así han hecho otros capitanes. ${ }^{45}$

No hay que olvidar además que esas figuras estaban aferradas al recuerdo de un lapso de muy pocos años (I5I7-I524), los únicos intensos y dignos de recordarse, la limitada zona de luz de su existencia mediocre:

Y más digo, que si como ahora los tengo en la mente y sentido y memoria supicra pintar y esculpir sus cuerpos y figuras y talles y maneras $y$ rostros y facciones como hacía aquel muy nombrado Apeles, o los de nuestro tiempo Berruguete y Miguel Angel y el muy afamado burgalés que dicen que es otro Apeles, dibujara a todos los que tengo dicho al natural o según entraba en las batallas, y el ánimo que mostraba cada uno.46

\section{III}

\section{Los "Memoriales" de Bernal Díaz y las "Crónicas" europeas}

Aislado en una pequeña capital de provincia, sabiéndose uno de los pocos sobrevivientes de la gran aventura, quizá descartara la posibilidad de que alguien - ¿quién sino él?- pudiera atreverse a tamaña empresa, la de contar sucesos intrincados, describir escenarios nunca vistos, transcribir con exactitud - aproximada-increíbles nombres indígenas...

45 Historia verdadera, B.A.E., CCVI, 308b; parte del párrafo se repite en el cap. CCIX, 310b. Lo mismo, con variantes de detalle, en la ed. de Genaro García, II, 472 y 480 .

46 Historia verdadera, loc. cit., en ambas ediciones. $\mathrm{Y}$ poco antes, dice: "no es mucho que se me acuerde ahora sus nombres, puesto que éramos quinientos cincuenta compañeros que siempre conversábamos juntos, así en las entradas como en las velas y en las batallas y reencuentros de guerra, y los que mataban de nosotros en tales batallas, y cómo los llevaban a sacrificar, por manera que comunicábamos los unos con los otros, en especial cuando salíamos heridos de algunas muy sangrientas y dudosas batallas, echábamos menos los que allí quedaban muertos". 
Podía, pues, considerar reservado para él ese período de historia que nadie intentaría por la dificultad, y estaba en el ímprobo pero grato trabajo de recomponer el enorme rompecabezas de sus anécdotas innumerables, fracasando siempre ante el gran esfuerzo de no perderse en los detalles o de no repetirlas más de una vez, cuando cayeron en sus manos varios libros imprevisibles para él, donde con la soberana facilidad del que sabe muy poco aunque tiene el secreto literario de expresarlo con elegancia, vio resueltas todas sus ideas.

No sabemos cuánto había avanzado en la composición de su obra cuando eso le ocurrió. En la primera redacción, en la del primer impreso ello parecía ocurrir cuando había concluido de contar las expediciones de Hernández de Córdoba y Juan de Grijalva (cap. XVII), y así lo ha dado por cierto la crítica. 47 Pero debe advertirse que en capitulos anteriores aparecen varias menciones de esos libros, ${ }^{48}$ lo que impide decidir con certeza: no es imposible que los leyera, cuando había avanzado bastante en la tarea, y volviera sobre las primeras páginas para intercalar sus observaciones indignadas.

Sea cuando fuera, ese acontecimento lo puso en la coyuntura de consi. derar sus memoriales desde una perspectiva literaria que no habia contemplado, con todas las perplejidades e incomodidades de la nueva situación de adoptar actitud de escritor, él, que juzgaba lo suyo como un testimonio oral, y obligado a medirse con profesionales de la literatura.

Aunque reclame en adelante para sus escritos el único precio que les corresponde por verdaderos, aunque proteste aquí y allá por su falta de letras latinas y por su rudeza, la lectura de los cronistas ejerció algún influjo que deja rastros: a ella debe atribuirse ese esfuerzo de muchos años, en los que trató de aliñar sus apuntes, y no a otra causa obedecen la media docena de reminiscencias clásicas que desparramó en su obra y que seguramente hubiera deseado multiplicar, ya que en lo fundamental no podía ampararse en otra autoridad que su memoria.

Con esos libros a la vista, interrumpió su tarea bruscamente:

Y quedarse ha aquí asi los despachos de Benito Martín como la armada

147 Genaro García, Noticias biobibliográficas de su edición de México, 1904, I, XIV; y Carlos Pereyra, citado por Ramón Iglesia, El bombre Colón, pág. 107.

tis Historia verdadera, B.A.E., caps. XIII v XIV, 12, y ed. Genaro García, I, págs. 40 y 43. En el lugar citado del cap. XIII, el impreso decía Francisco López de Gómara y Gonzalo Fernández de Oviedo; luego, el borrador dice Gómara, y Illescas y Jovio. 
del capitán Cortés, y diré como estando escribiendo esta relación vi las crónicas de los coronistas Francisco López de Gómara y las del doctor Illescas y las de Jovio, que hablan de las conquistas de la Nueva España; y lo que sobre ello me pareciese declarar, adonde hubiese contradicción, lo propondré clara y verdaderamente, y va muy diferente de lo que han es. crito los coronistas ya por mí nombrados (cap. XVII in fine).

Su primer impulso, después de la lectura, fue desistir: muy "groseras $y$ sin primor" le parecían sus palabras, comparadas con la "bretórica" y "policia" [elegancia] de los cronistas.

Pero volvió a leer las historias, y pasado el deslumbramiento de la forma artística inaccesible, comprobó con impaciencia cada vez mayor las numerosas inexactitudes (exageración enorme en el número de habitantes de México, matanzas copiosas sólo comparables con las de "Atalarico - Atila", destrucción de ciudades y templos, errores en la apreciación de los méritos de conquistadores, equivocación en pasajes particulares; pero lo que más le escandalizó fue la objetividad literaria de Gómara: ". . y dicelo de manera como si no fuera nada."). Concluyó entonces afirman. do que "la verdadera policía y agraciado componer es dceir verdad en lo que he escrito"; seguro ya de su propósito, anotó de paso que sobre su historia verdadera "pueden los cronistas sublimar y dar loas al valeroso y esforzado capitán Cortés, y a los fuertes conquistadores, pues tan grande empresa salió de nuestras manos"; y añadió con malevolencia, enfrentando a Gómara: ". . tenemos por cierto que le untaron las manos, pues que a su hijo el marqués que ahora es [Martín Cortés] le eligió [dedicó] su crónica, teniendo a nuestro Rey y señor, que con derecho se le había de elegit y encomendar". 49

¿Qué libros eran esos que exasperaban a Bernal Díaz? El objeto central de sus ataques era una obra que se divulgó largamente en pocos años, La ystoria de las Indias y la conquista de México de Francisco López de Gómara (r5Ir-ca. 1566), ${ }^{50}$ y que merecía el éxito alcanzado desde su primera edición (Zaragoza, I552); en cuanto a la Historia pontifical

149 Historia verdaderd, B.A.E., cap. XVIII, 15 y 16; ed. Genaro García (con variantes), cap. cit., I, pág. 49.

50 Se reproduio varias veces en España (Medina del Campo, 1553, y Zatagosa, 1554). Una real cédula del 17 de noviembre de 1553 -a la que tal vez no fuera ajeno fray Bartolomé de las Casas-ordenó recoger los ejemplares de la obra, que siguió editándose en el extranjero en su lengua original, Amberes, 1554, y en traducciones italianas, Roma, 1556 y Venecia, 1560 y 1565). Véase la nómina completa y descripción en José Toribio Medina, Biblioteca bispano-americana, I, 262270, y la edición de Joaquín Ramírez Cabañas, 2vs., México, 1943. 
de Gonzalo Illescas, y a la Historia general de todas las cosas sucedidas en el mundo en estos cincuenta años de nuestro tiempo, de Paulo Giovio (I483-I552) que tradujo del latín al castellano el licenciado Gaspar de Baeza y de la que hubo varias ediciones (Primera parte... Salamanca, 1562-1563; Primera y segunda parte... Granada, 1566), sólo se aluden como reflejos de la primera, y no se atacan en particular.51 En cambio, Bernal Díaz no se refiere para refutarlas a las Cartas de relación de Hernán Cortés, fuente principal de las narraciones subsiguientes de la conquista de México, aunque debió conocerlas impresas, y hasta cita alguna de ellas. ${ }^{52}$

No podía ignorar su existencia, lo que prueba la razón de su inquina; los que le exasperan son los advenedizos, los extraños a la conquista, que hacen de ella su botín literario, usurpando el lugar a los testigos. Tampoco se refiere a las Décadas de orbe novo (I530) de Pedro Mártir, en latín, que le hubieran provocado la misma impaciencia por idénticas razones. 53

Como se verá, y a pesar de sus protestas, el libro de Gómara fue utilísima lectura para el soldado de Cortés cuando revisaba sus originales, y le sirvió en alguna medida para aclarar sus recuerdos. $\mathrm{Y}$ para no volver sobre ello dejemos ya dicho que la Conquista de México tiene cualidades exclusivas, indisputables, de concepción y de forma, y que apreciarlas de ningún modo implica menoscabar las muy notables de la Historia verdadema: deben considerarse, desde el punto de vista histórico, testimonios complementarios - ambos parciales-, y dentro de la literatura - en la que ahora conviven-expresiones de dos mundos inconciliables, conformados por la vida y la cultura respectivas del clérigo humanista y del soldado historiador.

51 Bernal Díaz no fue el único español que teaccionó contra las inexactitudes -y la venalidad de Paulo Giovio - escritor veleidoso e interesado que clogiaba o denostaba indiferentemente según le conviniera. El conquistador Gonzalo Jiménez. de Quesada escribió contra él un voluminoso tratado que tituló Anti Jovio, publicado no hace muchos años (Bogotá, 1946). Véase además, sobre Giovio el juicio despectivo de E. Fueter, Historia de la bistoriografía moderna, Buenos Aires, 1953, II, 64-68, y las noticias de Medina, op. cit., I, págs. 320-327.

${ }_{52}$ Todas las noticias sobre la bibliografía europea de las cartas de relación, en José Toribio Medina, Biblioteca bispano-americana, I, págs. 89-90, 91, 91-92, 103-105, 106, 107-9, 127-134, y después en la Bibliografía de Hernán Cortés, que el mismo Medina dejó inédita, y que publicó póstuma la Biblioteca Nacional de Santiago de Chile.

53 Véanse las noticias bibliográficas sobre la circulación de las Décadas, en la edición de Buenos Aires, 1944, reunidas por Joseph H. Sinclair, y publicadas antes en el Boletín de la Academia Nacional de la Historia, Quito, v. X, enero-mayo de 1930, núm. 27-29, págs. 18-43. 
Como lo ha señalado Ramón Iglesia, Francisco López de Gómara concibe su historia de la conquista a modo de biografía ejemplar: así la entendían Polibio y Salustio, por ejemplo; y ordena el cuadro en torno a la figura de Cortés, cuyo genio militar exalta. El mismo procedimiento siguió en otros escritos suyos históricos (Crónica de los Barbarrojas, Anales del Empisador Carlos V): "Dos maneras hay, muy ilustre señor de es" crebir historias. La una es cuando se escribe la vida, la otra cuando se cuentan los hechos de un emperador o valiente capitán": la biografía moral, psicológica, o la externa, que se refiere a sucesos importantes para su época. $Y$ en cuanto a composición literaria, apreciaba sobre otras cualidades la concisión sintética y aguda que se logra seleccionando entre muchas noticias, las de mayor curiosidad: "Contar cuándo, dónde y quién hizo una cosa, bien se acierta; empero decir cómo es dificultoso; así, siempre suele haber en esto diferencia." 54

No importa decidir si además, influyeron para mover su pluma otras razones, por ejemplo el hecho de que estuviera efectivamente vinculado a la casa del Marqués del Valle como capellán; que hubiera recibido mercedes; y que, eventualmente, esperara otras de ese libro que dedicó al hijo de Hernán Cortés: en todo caso, el tono de su crónica no es el de elogio exaltado, sin reservas; a pesar de lo que Bernal Díaz afirma, abunda en toques críticos y maliciosos, y por lo demás, el autor sólo con. taba con la documentación que provenía de Hernán Cortés.

No fue Bernal Díaz el único que recordara su falta de independencia. Las Casas que nunca ocultó su aversión por Gómara, retribuyendo ironías, dice de él entre muchos otros cargos:

Gómara, clérigo, que escribió la historia de Cortés, que vivió con él en Castilla siendo ya marqués, y no vido cosa ninguna ni jamás estuvo en las Indias, y no escribió cosa sino lo que el mismo Cortés le dijo, compone muchas cosas en favor de él, que, cierto, tho son verdad...55

Y la misma opinión recogió el Inca Garcilaso a fines de siglo: "Es fama cierta, aunque secreta, que la escribió [la Conquista de México] el mismo que la conquistó y ganó dos veces." 56 Lo que realmente importa ave-

54 Dedicatoria de la Crónica de los Barbarrojas, pág. 331, e Historia general de las Indias, B.A.E., 155, cit. Ramón Iglesia, Cronistas é bistoriadores, pág. 100.

55 Histoira de las Indias, II, pág. 476. A Las Casas se le atribuye, como es sabido, la prohibición del libro de Gómara, Vid. Medina, Biblioteca bispano-americana, II, págs. 262-70.

56 Historia general de Perú, primera parte, cit. R. Iglesia. 
riguar es si los hechos de Hernán Cortés justificaban la devoción de su panegirista. Y para ello, debemos atenernos a los dichos del testigo más indudable, Bernal Díaz, que admira incondicionalmente a su jefe y no deja de añadir a su nombre los calificativos insistentes de "valeroso, esforzado, animoso, venturoso"; elogia su habilidad, pondera la pureza de sus cuatro linajes, admira su elocuencia y su cultura, su celo en el deber, su señorío, su afabilidad, su piedad, su dominio de sí mismo, su caridad, su lenguaje pulido y sobrio, sin demasías de soldado... Un largo capítulo dedica a pintar los rasgos físicos y morales de su capitán, en el que a la enumeración de cualidades, opone leves debilidades del hombre que conoció en los combates ("Era aficionado a juegos de naipes y de dados... era en demasía dado a las mujeres y celoso en guardar las suyas"). ${ }^{57}$

A su capitán de México nadie más que él, Bernal Díaz, puede profesar cariño más razonado; nadie entre los vivos sino él puede dar testimonio de su genio militar; sólo él es capaz de poner en evidencia sus virtudes esenciales, y su elogio sería, sin duda, el que Cortés hubiera preferido. Por eso le enfurecen esas alabanzas desconsideradas que lee. Una sola cita nos evitará acudir a muchísimas otras:

$\mathrm{Y}$ puesto que [aunque] fue tan valeroso y esforzado y venturoso capitán, no lo nombraré de aquí delante ninguno de estos sobrenombres de valeroso ni esforzado ni marqués del Valle sino solamente Hernán Cortés; porque tan tenido y acatado fue en tanta estima el nombre de solamente Cortés, así en todas las Indias como en España, como fue nombrado el nombre de Alejandro en Macedonia, y entre los romanos, Julio César y Pompeyo y Escipión, y entre los cartagineses Aníbal y en nuestra Castilla Gonzalo Hernández de Córdoba el gran capitán; y el mismo valeroso Cortés se holgaba que no le pusiesen aquellos sublimados dictados sino solamente su nombre, así lo nombraré de aquí adelante.58

Así como se le iluminaban en el recuerdo esos años de penurias heroicas pasadas con Cortés, soldado y camarada, la imagen posterior del cortesano, del "Marqués del Valle" que sólo alcanzaron a conocer sus ac441.

57 Historia verdaderd, B.A.E., cap. CCIV, 298; ed. Genaro García, cap. cit. II,

58 Historia verdadera, B.A.E., cap. CXCIII, 277, y ed. García, II, 370-371. El párrafo citado en el texto en la ed. de Genaro García, cap. XIX, 55; no está en la ed. príncipe. 
tuales admiradores, entra en la zona oscura de los años sin gloria que vinieron después, y de ella sólo saca notas despectivas.

Su admirado capitán, es cierto, incurría a veces en errores, sobre todo cuando desoía los consejos de sus compañeros:

... era muy porfiado, en especial en las cosas de la guerra, [que] por más consejos y palabras que le decíamos en cosas desconsideradas de combate y entradas que nos mandaba dar cuando rodeamos los pueblos grandes de la laguna . . .59

Pero la terquedad es virtud de soldado, y el primer Cortés, que en la imaginación de Bernal Díaz es el único, cumple cabalmente hasta con sus defectos, el modelo del guerrero.

Después de la toma de México, surgió el otro Cortés, el político, apenas entrevisto antes en algunas ocasiones: en las maniobras de Veracruz; y al llegar al ansiado reparto de las riquezas, por ejemplo. Era ese Mar. qués del Valle, extraño a los conquistadores, tan deslumbrante para los cortesanos como desventurado en todas las empresas guerreras que intentó, totalmente mudado en lo físico, y bastante en lo moral. A ese "Marqués del Valle" conocieron los cronistas europeos:

... no hay memoria de ninguno de nosotros en los libros e historias que están escritos del coronista Francisco López de Gómara ni en la del doctor Illescas que escribió el Pontificial ni en otros modernos coronistas, y sólo "el marqués Cortés" dicen en sus libros que es el que lo descubrió y conquistó y que los capitanes y soldados que lo ganamos quedamos en blanco...60

LOS "TESTIGOS" Y LOS "CRONISTAS"

Hacia mediados del siglo xvi concluía el primer ciclo de la historia de América, el de la conquista, y se prolongaba el segundo, que había empezado ya con la población y fundación de ciudades, menos brillante

59 Historia verdadera, B.A.E., CCIV, 299, y ed. Genaro García, II, cap. cit. II, 443 .

60 Historia verdadera, B.A.E., cap. CCX, 312; ed. Genaro Garcia, II, 486. 
pero tan laborioso como el primero. A los "conquistadores" (más o menos "antiguos" según la fecha de su llegada), habían sucedido los "pobladores", más aprovechados, porque encontraron ya en paz la tierra.. Y los primeros se esforzaban en que no se olvidara su privilegio frente a los segundos, para defender una categoría o "estado" adquirido, sobre todo porque de hecho se prescindía de esos méritos para los honores y recompensas.

En 1551, quince años antes de su muerte, fray Bartolomé de las Casas se recluia a corregir su obra mayor, sin que rehuyera desde su celda participar en los casos de la cuestión teórica que había promovido él mismo; y al año siguiente salían a la luz, con su apasionada Destruyción de las Indias, algunos de los folletos polémicos de la campaña concluida. Pocos años más viviría Gonzalo Fernández de Oviedo, rudamente aludido también entre los del bando de los "encomenderos" (I557), y diez años antes había muerto Hernán Cortés (1547), también atacado por el fervoroso dominico.

Aún no habían pasado diez años, y no se habían serenado los ánimos de los conquistadores, rebelados cuando se publicaron las Leyes nuevas que en $154^{2}$ abolieron el servicio personal de los indígenas: seguía agitándose el problema de la perpetuidad de las encomiendas que la Corona se resistía a conceder, a pesar de las peticiones insistentes de los conquistadores. Nada había resuelto la junta convocada en Valladolid, a la que Bernal Díaz del Castillo concurrió como conquistador viejo, para resolver con el Consejo de Indias el problema planteado, ${ }^{61}$ pero a nadie podía ocultársele ya, ni a los conquistadores viejos ni a sus hijos, a menudo postergados en el reparto de las mercedes, que, aun en caso de lograrse, esas recompensas eran muy precarias y serían siempre inferiores a las esperanzas. En cambio, la aparición de los primeros relatos del descubrimiento y conquista que se difundieron en seguida en varias lenguas vino a probar que la literatura podía asegurar una posteridad más larga y tranquila. ${ }^{62}$

61 Historia verdadera, ed. Genaro Garcia, II, cap. CCXI, págs. 490-94.

62 Después de las Cartas de relación de Cortés $\left(2^{a}, 3^{n}\right.$ y $4^{a}$, publicadas entre 1522 y 1525), el Sumario de la bistoria natural (1526) de Gonzalo Fernández de Oviedo, las Décadas de Orbe Novo de Pedro Mártir (1533) y la primera parte de la Historia general de las Indias (1535) de Oviedo, aparecieron la Primera parte de la Crónica del Perí (1553) de Pedro Cieza de León; la Verdadera relación de la conquista del Perú (1555) de Francisco de Jerez, la Historia del descubrimiento $y$ conquista del Perú (1555) de Agustin de Zárate, y los Naufragios y comentarios (1555) de Alvar Núñez Cabeza de Vaca y Pedro Hernández. 
Entre los productos de esa literatura flamante pueden distinguirse claramente dos líneas que a veces se confundieron: la de los testigos de la conquista - letrados o conquistadores-, y la de los que, desde España, escribían sobre "relaciones": la que comienza con las cartas de Colón, frente a la que viene de las de Pedro Mártir.

Los testigos, muy a regañadientes, admitían compartir esa "materia de Indias", que era el más ilustre episodio de sus vidas - y su título de nobleza-, con esos intelectuales curiosos de lo nuevo y de lo exótico que escribían en sus gabinetes lo que no habían visto. A Gonzalo Fernández de Oviedo le sorprendía la intrepidez de Pedro Mártir escribiendo al Papa, a Reyes y a principes sobre cosas de esas Indias que no conocía, "arrimado [apoyado] a su elegante estilo"; ${ }^{33}$ y el Inca Garcilaso de la Vega, al recordar a un soldado apostrofando por la calle al cronista que había errado, gracias a los informes de terceros, ${ }^{6:}$ manifestaba la susceptibilidad rigurosa que en punto a verdad sentían los criollos o indianos que habían vivido en América, en cuanto hojeaban un escrito forjado en España.

Ellos oponían vistdd recta en la narración de los hechos, a buena retórica, policía, elocuencia, ornato encumbrado, estilo delicado, cualidades todas de la literatura pero no de la realidad vivida y sufrida.

No se resignaban a admitir que en la "materia de Indias" entrara la imaginación como ingrediente, lo mismo que en la "materia de Bnetaña" o en la "de Francia". Si el haber cruzado el océano era circunstancia que transformaba para siempre a los hombres, el haber asistido a la conquista debía conferir la primacía o la exclusividad en el relato de esa experiencia inolvidable. Porque nada de lo que pudiera aprenderse en Europa servía para subsistir en América: si no bastaba haber cursado meritoriamente las guetras de Italia para afrontar las de los indios ( $y$ asi lo probaron fracasos numerosos de capitanes avezados que sucumbieron en la primera emboscada), ${ }^{65}$ ¿Cómo podría aplicarse a la narración de esa historia cercana e insólita el modo de composición literaria de los hechos de la antigüedad?

63 Gonzalo Fernández de Oviedo, Historia general y natural de las Indias, I, pág. 10 .

6. Inca Garcilaso de la Vega, Comentarios reales, lib. V, cap. 40.

65 Bernal Díaz del Castillo, Historia verdadera, ed. Genaro García, cap. CXCIV, II, págs. 375-76. Después de contar cómo los indios zapotecas mataron al capitán Barrios, veterano de Italia, concluye: "Verán cuánto va de los conquistadores viejos a los nuevamente [recién] venidos a Castilla, que no saben qué cosa es guerra de indios ni sus astucias". 
Es muy curioso revisar los lugares sucesivos de la Conquista de México, que Bernal Díaz corrige por inexactos. El examen lo ha hecho ya Ramón Iglesia, y de él resulta que, en su mayoría, los errores que señala no afectan al relato de los episodios más importantes. Son enmiendas de pormenor las que hace; y también es cierto que en ocasiones interpreta mal párrafos de Gómara y le enrostra afirmaciones inexistentes en su libro, siempre achacándolas rencorosamente a los que lo informaton, a los que "no le dieron buena cuenta", para que arrastrara tras sus errores a Illescas y a Jovio. ${ }^{66}$

Mayor significado tienen las ocasiones en que se desmiente el resentimiento personal de Bernal Díaz, cuando mañosamente invoca los derechos de la verdad, y se irrita desproporcionadamente por insignificantes traspiés de Gómara al colocar a Cortés en episodios menores, en los que no estuvo, y que no eran, en verdad, sino pequeñas escaramuzas o reconocimientos; porque como él mismo lo ha reconocido, Cortés "era el primeto en el trabajo y en las batallas". ${ }^{67}$

Bernal Díaz, a pesar de esas protestas de afecto por su jefe y aunque trate de disimular su resentimiento, sabe que la leyenda que ataca en Gómara se había iniciado antes, en la correspondencia que Cortés enviaba al Emperador sobre los progresos de la conquista. Más de una vez recuerda los elogios tardíos que el Marqués del Valle hizo de sus capitanes y soldados, y en una de ellas dice:

.. si esto que ahora dice Cortés escribiera la primera vez que hizo relación a su majestad de las cosas de Nueva España, bueno fuera; mas en aquel tiempo que escribió a su majestad, toda la honra y prez de nuestras con. quistas se daba a sí mismo, y no hacía relación de cómo se llamaban los capitanes y fuertes soldados, ni de nuestros heroicos hechos, sino escribía a su majestad: "Esto hice, esto otro mandé hacer a uno de mis capitanes", e quedábamos en blanco hasta ya a la postre, que no podía ser menos de nombrarnos. 68

Le preocupaba insistentemente a nuestro cronista que la gran obra co.

66 Ramón Iglesia, Cronistas e bistoriadores, págs. 139-151, y Joaquin Ramirez Cabañas, introducción y notas a la Historia de la conquista de México de Gómara.

167 "... ciertamente, en todas las batallas se hallaba de los primeros", Historia verdadera, ed. Genaro García, I, cap. LXIX, pág. 200; "... siempre en las batallas le vi que entraba en ellas juntamente con nosotros", op. cit., II, CCIV, 441.

68 Historia verdadera, B.A.E., cap. CCV, 300; párrafo abreviado después en el "borrador", ed. Genaro García, II, 446. 
lectiva de la conquista se concibiera a través de Gómara como la hazaña de Cortés, cuyas decisiones personales trata siempre de atribuir al consejo de sus capitanes y soldados más próximos, y de desvanecer en plurales inclusivos. "Parece ser que a los soldados nos daba Dios gracia y buen consejo para aconsejar que Cortés hiciese las cosas muy bien hechas": a ese juicio y acuerdo anónimo se deben siempre los resultados venturosos y los éxitos más importantes.

$Y$ de hecho, es difícil tachar la veracidad de Bernal Díaz en esa afirmación, porque uno de los recursos de la habilísima táctica de Cortés parece haber sido siempre provocar juntas de capitanes en las que, a fuerza de astucia y usando de su ascendiente personal, resultaba recogiendo como opinión general el criterio que él mismo tenía adoptado de antemano.

Bernal Díaz, soldado anónimo, no podía aspirar-bien lo sabía él- a ocupar con su nombre la atención de la historia, tal como se concebía entonces. La prosperidad y condición expectable de sus últimos años se debía sólo - también lo sabía él-a la circunstancia de haber sobrevivido a sus compañeros, y no a prodigios personales de valor que, en todo caso, sólo podían recordar los testigos. Nunca había sido capitán, y es improbable que fuera alguna vez sargento (o alférez) como dice corrigiéndose al hablar de la expedición de Grijalva. ${ }^{69}$

Así dio en imaginar la historia pasada desde un punto de vista que lo enaltecía, igualando a jefes, capitanes y soldados, y clasificándolos con los únicos criterios válidos para él de la lealtad, de la astucia, y del valor. De ello resulta una singular perspectiva, enteramente nueva de la historiografía del siglo xvi, y que muy pocos contemporáncos estaban preparados para apreciar. No era necesario para ello disminuir a Cortés: "Las cosas del valeroso e animoso Cortés - se dice repetidamente- han de ser siem. pre muy estimadas y contadas entre los hechos de los valerosos capitanes".70 Se trata de ganar para sus soldados, migajas de esa gloria, que sólo así, colectivamente, puede alcanzar él, Bernal Díaz, y sus descendientes.

69 Historia verdadera, ed. Genaro García, I, cap. VIII, 27; "me mandó Diego Velásquez que viniese con aquellos capitanes por alférez (borrado, en el original, sargento)", párrafo que no aparece en la edición príncipe.

70 Historia verdadera, ed. Genaro García, II, cap. CCX, pág. 486. 
Al historiador educado en las humanidades y asistido por sus reminiscencias clásicas debía parecerle suficiente razón y motivo para explicar el triunfo de un puñado minúsculo de hombres contra un enorme imperio la circunstancia de que los mandara César, Alejandro o Cortés. Enorme esfuerzo tiene que costarle al testigo vulgar de todos los tiempos, en cambio, concebir la unidad de una grande empresa, porque la descompone en una suma de pequeños éxitos y fracasos, lo mismo que se resiste a buscar, para explicarla, causas que presupongan la actividad decisiva de hombres y de móviles superiores a la talla normal. Los contemporáneos del descubrimiento de Indias forjaron aquella leyenda satisfactoria del navegante anónimo que habría legado sus mapas y papeles a Colón, habilitándolo, así, para su viaje: Gómara y el Inca Garcilaso no fueron los únicos en darla como verdad sabida.

Bernal Díaz se resiste a admitir que la historia sea la simplificación elaborada de la realidad que ha vivido, porque en esa versión artística no hay lugar para los pormenores donde su nombre podría aparecer, y se aferra tercamente a ese otro modo vulgar de evocación minuciosa, donde las grandes líneas de la historia se quiebran y despedazan en anécdotas sucesivas.

No sería propiamente falta de letras lo que impedía a Bernal Díaz colaborar a que creciera la leyenda de las hazañas de Cortés. Lo que estaba escribiendo nuestro cronista era una especie de memorial colectivo, en el que defiende los derechos de los desposeídos de los bienes de la Fama, de los "verdaderos conquistadores", defraudados, según él, por Cortés cuando se repartieron las mercedes, y nuevamente postergados en sus derechos a sobrevivir con sus nombres, como cabezas de linaje, esta vez por obra de Gómara y sus secuaces. Esa identificación apasionada confiere su originalidad y extrañeza a la Historia, aunque no asegure la infalibilidad de sus juicios, que provienen de una facción, aún devota de Cortés pero dolida por el juicio de la historia que ha enaltecido sólo al Marqués del Valle. Bernal Díaz se consideraba, ya lo sabemos, un "verdadero conquistador", el más antiguo de los venidos a México antes que Cortés; pero tentaba ahora la oportunidad de que se le considerara con su nombre en Ia reseña de los "sobresalientes" en el valor, entre los "fuertes conquistadores", sin atender demasiado a jerarquías de nacimiento ni a grados efectivos en la milicia. 


\section{V}

\section{BERNAL DíAz, ESCRITOR}

Bernal Díaz no era siempre sincero cuando se consideraba fuera de los dominios de la literatura, y la caprichosa justicia que rige los cambios de gusto estético ha satisfecho con creces sus deseos íntimos. Pocos dejan de encontrar extraño encanto en su espontaneidad; la verdad de su $H i s$. toria, que le parecía innegable bien y único suyo, puede merecer - en cambio-algunas reflexiones dubitativas.

Que secretamente deseara compartir el éxito de Gómara, de Illescas o de Jovio parece indisputable, a pesar de sus declaraciones de modestia fingida. $Y$ ya el prólogo de la primera edición contenía una frase final que prueba cómo confiaba en el valor literario de sus apuntes: "Pido por merced a los señores impresores que no quiten ni añadan más letras que las que aquí van, e suplan, etc..." Si así no fuera ¿por qué revisaba y corregía tan minuciosamente sus escritos y consultaba sus dudas con los conquistadores que le auxiliaban con sus recuerdos? ${ }^{71}$ ¿Por qué rehacía capítulos, volviendo a redactar párrafos y páginas enteras, con muy curiosas vacilaciones literarias, que han dejado huellas en la copia de Remón y en el borrador de Guatemala ?72 ¿Por qué daba a leer su "Historia" a "letrados" y a "caballeros curiosos", que sólo serían capaces de opinar sobre lo literario? ¿Qué otra actitud sino la del escritor manifiestan algunas arengas que pone en boca de Cortés, y las referencias a la historia romana, ${ }^{73}$ si no queremos fijarnos en otras más vulgares a sucesos del An-

71 "Ya (he) escrito a México a tres amigos que se hallaron en todas las más conquistas para que me envíen relación, para que no vaya así incierto". Párrafo que no aparece en el impreso, y que está tachado en el ms. de Guatemala: Historia verdadera, ed. Genaro García, I, cap. LXXX, 234.

72 He examinado, a través de la edición de México, 1955, que las trae en nota, las correcciones del manuscrito de Guatemala: sobre unas treinta y dos enmiendas o supresiones, solamente seis con cifras corregidas; veintiséis son correcciones de estilo; y entre ellas, diez, las más curiosas, se deben al escrúpulo de caer en malediciencias, por lo que parece. Vid. Historia verdadera, ed. cit., I, cap. VIII, 59; XVI, 77; XLI, 135; LIX, 178; XXXIV, 116: LXXXVII, 260; CI, 315; CVII, 329; CXXV, 382; CXXIX, 405 y 412; CXXXVI, 433, 434; CXLVI, 466; CLII, 436; II: CLVIII, 80; CXIV, 123; CLXVI, 130; CLXX, 174; CLXXII, 183; CLXXVI, 200; ClXXVIII, 213; CLXXXVI, 230; CXC. 253; CXCI, 258; CXCIII, 268; CXCIV, 272; CXCVI, 292; CCI, 212, 313, 314 y 315; CCII, 320; CCIV, 333; CCV, 333, 338; CCVI, 351, 353 y 355; y cap. CCXII, 374-376.

7.3 "Yo he leído la destrucción de Jerusalem" [es decir, Josefo], cap. CXLVI, 64; al llegar a Cuba con los ídolos, a la vuelta de la expedición de Hernández de Córdoba, las gentes suponían que ésos debían de ser "los judios 
tiguo Testamento, ${ }^{74}$ o a la más inmediata literatura de caballerías ?75

Hay que suponer que debió ser grande la diferencia entre los "memoriales" o "relación" que se propuso al principio, a solas con sus recuerdos y con sus resentimientos, y la "Corónica" que tantos leyeron manuscrita, y que se juzgó digna de enviarse al Consejo de Indias. Entre los unos y los otros se interpuso la lectura de Gómara, de Jovio, de Illescas y de Las Casas; aunque sólo nos diga su impaciencia, usó esos libros como modelo literario, y como fuente histórica complementaria. Entre la fecha de los "memoriales" y la de la "corónica" fue creciendo, además, la opinión que de sí mismo tenía el autor, a medida que la historia ulterior le subrayaba el cuadro de la conquista de Nueva España como la época más gloriosa - no deslucida por guerras civiles como la del Perú-y se veía en ella como único relator actual, y cada vez más respetado sobreviviente.

Había empezado a escribir sus apuntes sin pretensiones literarias, puesto que hablaba en nombre de los de abajo; y desdeñando artificios imposibles, dio con la suma naturalidad que rara vez se fija por escrito, porque se interponen siempre para rectificarla exigencias y convenciones de la lengua literaria que nadie se atreve a contravenir.

Esa consigna inicial de buen sentido no se desmintió, a pesar de las correcciones posteriores. Alguna vislumbre del éxito póstumo que esperaba a sus escritos llegó a tener cuando cierto licenciado los examinó, y después de afearle las muestras de vanidad excesiva que advertía, y de desconfiar de su memoria prolija, elogió con acierto sus cualidades de escritor:

... en cuanto a retótica - le dijo-va [la Historia] según nuestra común habla de Castilla la Vieja, y que en estos tiempos se tiene por más agradable, porque no van las razones hermoseadas ni de afeiterias que suelen componer los coronistas que han escrito cosas de guerras . . .76

que desterró Tito y Vespasiano", cap. VI, 56; las fiestas por la paz entre Francisco I y Carlos $\mathrm{V}$ le recuerdan a Bernal Díaz las de los cónsules y emperadores romanos al volver de sus campañas (CCI, 420); Cristóbal de Olid le parece un Héctor en esfuerzo (CCV, 446), y Juana Mansilla una matrona romana (CLXXXVIII, 345); Cortés usa a menudo reminiscencias clásicas en sus arengas (véanse caps. LIX, $167 \mathrm{y}$ CLVI, 130); pero sus capitanes también las invocan, y Narváez, por ejemplo, dice a Garay que Cortés es comparable a Julio César, Octaviano y Aníbal (cap. CLXII, 185).

74. Historia verdaderd, XXXVII, 104.

75 Al divisar las torres de la ciudad de México, Bernal Díaz recuerda el Amadís de Gaula; y a Pedro de Ircio lo llama Agrajes sin obras (CCV, 446).

76 Historia verdadera, cap. CCIX, 495. 
La intuición certera de ese licenciado se ha confirmado después. La Historia de Bernal Díaz se cuenta entre los libros que enumera como fuente el Diccionario de autoridades, y el único estudio lexicográfico que hasta ahora se ha intentado considera que el vocabulario de nuestro cronista es el repertorio más abundante para colmar el vacío que media entre el Vocabuhario de Nebrija y el Tesoro de Covarrubias (I496-I6ri).77 Curiosa comprobación: ese soldado español, que había dejado su patria a los diez y ocho años, conservaba en la vejez su lengua materna apenas contaminada de indigenismo: menos de un centenar sobre un total de cuatro mil trescientos vocablos.

\section{VI}

\section{LA HISTORIA DE LOS "SOLDADOS"}

La literatura española es particularmente rica en relatos vividos por capitanes y soldados, viajeros o vagabundos medio aventureros a quienes tocó incorporarse en cualquier forma al prodigioso movimiento de expansión de España en los siglos xv y XvI, y que quisieron dejar su testimonio personal de ese momento histórico cuya trascendencia comprendieron más o menos oscuramente, y en el que inscribieron sus vidas, sus trabajos y sucesos.

Sabían que inauguraban un género nuevo: algunos buscaron a tientas relacionar sus escritos con otros ya ilustrados en la antigüedad, esforzándose infructuosamente en asociar sus cartas de soldados a los Comentarios de César o Salustio; o sus descripciones de la naturaleza a la enciclopedia de Plinio; casi todos, escritores improvisados y sin letras, comprendieron que era imposible esa competencia con los modelos inimitables, y confiaron en que la posteridad apreciaría la desnuda y desmañada verdad de sus escritos.

Oviedo, por ejemplo, oponía a los dos mil millares de libros que Plinio había usado, su experiencia acumulada "en mil millones de trabajos, e necesidades e peligros en veinte e dos e más años que ha que veo y experimento ... estas cosas."

77 Elbert Daymond Turner, The vocabulary of Bernal Diaz del Castillo's "Historia verdadera de la conquista de la Nueva España". Tesis de la Universidad de North Carolina, 1949, cuyo microfilm debo a la gentileza de la profesora Frida Weber de Kurlat. 
En esa literatura miscelánea y osadamente antirretórica se estima sobre todo la curiosidad de las noticias, y se desprecia el aliño de la forma, pero en ninguna obra de esa familia se profesa como en la Historia verdadera un desdén más explícito por las conveniencias del género histórico, ni hay otra que más desenfadadamente se desentienda de ellas. Aunque se inserte continuamente en el relato, Bernal Díaz no sólo no aspira a lograr un estilo personal, sino que acierta instintivamente con los recursos que borren su individualidad, confundiéndose con las voces de una muchedumbre anónima que reclama su ingreso en la historia. Eran los que habían salido a scrvir a su Rey y a difundir la fe, según las fórmulas consagradas; pero también - porqué no confesarlo-a ganar honra y fama, y a la espera de recompensa. Son los que no temen confesar su terror ante las batallas y su miedo a la muerte. Bernal Díaz reproduce minuciosamente y con elocuencia enfática las cualidades y defectos de esa entidad humana, vulgar y querellosa; desconfiada, brutalmente franca, pero taimada por resentimiento; leal a su jefe pero murmuradora; ignorante o presta a olvidar cualquier superioridad que no se funde en la aptitud física del valor o la voluntad; capaz de creer sólo en lo que se ve y se toca, misterios de la religión aparte. La vida se encargó de promover a Bernal Díaz a la tarea honrosa de albacea de sus compañeros, y compuso con admirable congruencia ese alegato donde parece oírse la voz de todos. Por él habla ese saldo de los sobrevivientes desquiciados por una honda sacudida - por una gran ilusión; de los que muy difícilmente recomponen normas de conformidad con lo que les queda, porque recuerdan como una revelación el cuadro del portento que vivieron.

Julio CAillet-Bois

Universidad de Buenos Aires, Visitante de la Universidad de California, Los Angeles. 